\title{
EL PROFESIONAL DE ENFERMERÍA: UNA PERSONA CUIDANDO PERSONAS
}

\author{
Ángela PAREDES AGUIRRE 1
}

Las diversas antropologías, no cristianas, describen un perfil sombrío y profundo antihumanitario del ser humano.

Generan una confusión acerca del origen y la identidad del hombre lo que ha llevado a aberraciones y discriminaciones de todo tipo.

La Biblia enseña desde el primer capítulo de Génesis que el universo, la vida de los animales y las personas provienen de Dios. Él formó al hombre y a la mujer a su imagen y semejanza, para que se multiplique, gobierne la naturaleza con justicia, misericordia y respeto.

El concepto de persona creada es fundamental para determinar las actividades que ayuden a proteger la salud y a curar la enfermedad.

Como personas creadas por Dios tenemos la responsabilidad moral de brindar un servicio profesional profundamente religioso, porque las personas a quienes cuidamos son hijos de Dios (Génesis 1:27, Deuteronomio 14:1 y 1Juan 3:1).

La noción filosófica de "persona" suele referirse a un ser humano que presenta un alto nivel de racionalidad, conciencia, imaginación, creatividad, espiritualidad, capacidad de sentir, expresar deseos, esperanza y sentir sensaciones de amor, justicia y paz.

Tal como la ética de Adán debe ser la ética del profesional de enfermería. En primer lugar, debería saber quién definía lo que era correcto e incorrecto, no era el hombre sino Dios. Nunca fue el plan de Dios que el hombre determinase los valores éticos.

Así, el profesional de enfermería es libre de elegir si acepta o rechaza la conducta que Dios le pide, la decisión de que esta conducta es buena o mala es asunto que está bajo el dominio y soberanía de nuestro Dios.

El profesional de enfermería como persona que cuida a otras personas debe evidenciar una conducta ética basada en los principios de amor, justicia y autonomía.

El verdadero sentimiento humano jamás nace de una emoción puramente personal; nace por razones que están fuera del ser humano, es decir que tiene una influencia divina.

El principio de amar al prójimo como a uno mismo, junto a la expresión de San Pablo de que el Creador "de una sangre ha hecho todo el linaje de los hombres” según lo registra Hechos 17:26 constituye el fundamento de la conducta ética de los profesionales de enfermería.

El amor por cuidar de los seres humanos debe regirse por hacer y promover el bien, prevenir y no infringir daño a nadie. El poder del amor estaba en todas las obras de curación de Cristo y solamente siendo partícipes de este amor se puede ser instrumentos eficaces para su obra de la restauración de la salud.

Se debe buscar el mayor bien tanto a nivel individual como social. A nivel individual debe reconocerse que cada parte del cuerpo tiene un valor, está tan bien organizado que allí radica la razón de su ser, su perfección.

Asimismo, reconoce que pertenece a una sociedad a la que debe respeto y tiene el compromiso moral de aspirar a una sociedad más justa.

El principio de justicia debe ocupar una posición prioritaria. Significa tratar a las personas con la misma consideración, teniendo en cuenta su individualidad, brindando cuidado eficiente, efectivo y oportuno a la persona, familia y comunidad sin interrupción temporal durante todas las etapas de la vida en los estados de salud y enfermedad.

Dios nos pide no hacer distinción de personas en el juicio (en el cuidado) porque todas las personas tienen iguales derechos para alcanzar lo necesario para su plena salud y desarrollo.

El respeto a las personas es importante porque reconocemos que todos somos hijos de Dios digno de los

${ }^{1}$ Enfermera, Magíster en Educación de Enfermería. Directora de la Escuela Académico Profesional de Enfermería de la UPeU. 
cuidados de enfermería. En mérito a su dignidad personal, el ser humano es siempre un valor en sí mismo y por sí mismo, y como tal exige que se respete su autonomía teniendo en cuenta sus decisiones eminentes de sus valores y convicciones personales.
El enfermero(a) como persona que cuida personas aplica estos principios en su ejercicio profesional que constituyen directrices básicas que gobiernan su conducta ética.

\section{REFERENCIAS BILIOGRÁFICAS}

\section{Santa Biblia}

2. Red de Enfermería en América Latina.

3. Richardson \& Webber citado por Rumbold. Ética en Énfermería. Editorial Mc Graw Hill.3ra. edición. México.
4. Veloso Mario. Filosofía de la obra médica adventista.

5. White Elena. Consejos sobre salud. ACES Argentina.

6. White Elena. Historia de la redención. ACES Argentina. 